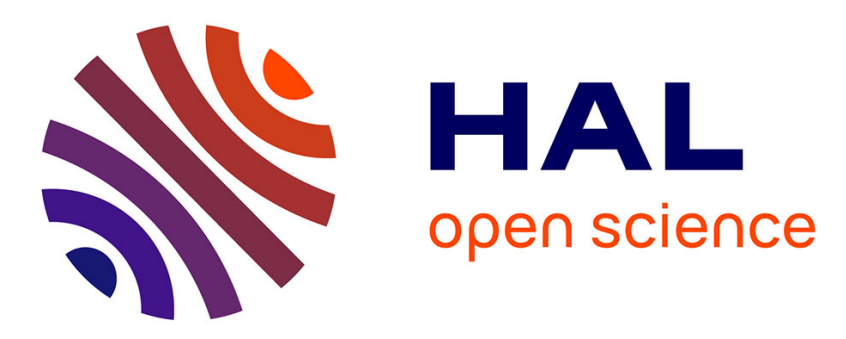

\title{
Structure of the carbon layers deposited on the toroidal pump limiter of Tore Supra
}

Céline Martin, Rémi Ruffe, Cédric Pardanaud, Martiane Cabié, Christian

Dominici, Timo Dittmar, Pascal Languille, Bernard Pégourié, Emmanuelle

Tsitrone, Pascale Roubin

\section{To cite this version:}

Céline Martin, Rémi Ruffe, Cédric Pardanaud, Martiane Cabié, Christian Dominici, et al.. Structure of the carbon layers deposited on the toroidal pump limiter of Tore Supra. Journal of Nuclear Materials, 2010, 10.1016/j.jnucmat.2010.11.006 . hal-00542718

\section{HAL Id: hal-00542718 \\ https://hal.science/hal-00542718}

Submitted on 7 Dec 2010

HAL is a multi-disciplinary open access archive for the deposit and dissemination of scientific research documents, whether they are published or not. The documents may come from teaching and research institutions in France or abroad, or from public or private research centers.
L'archive ouverte pluridisciplinaire HAL, est destinée au dépôt et à la diffusion de documents scientifiques de niveau recherche, publiés ou non, émanant des établissements d'enseignement et de recherche français ou étrangers, des laboratoires publics ou privés. 


\title{
Structure of the carbon layers deposited on the toroidal pump limiter of Tore Supra
}

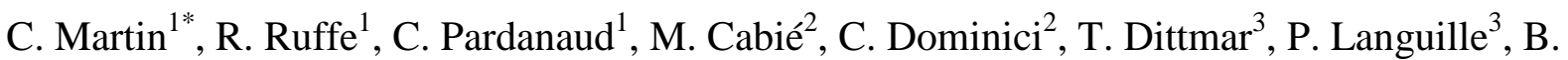 \\ Pégourié $^{3}$, E. Tsitrone ${ }^{3}$ and P. Roubin ${ }^{1}$ \\ ${ }^{1}$ PIIM, CNRS-Université de Provence, Centre St Jérôme, 13397 Marseille cedex 20, France. \\ ${ }^{2}$ CP2M, Université d'Aix Marseille III, Centre St Jérôme, 13397 Marseille cedex 20, France. \\ ${ }^{3}$ CEA/IRFM, 13108 Saint-Paul-lez-Durance, France.
}

\begin{abstract}
Scanning and transmission electron microscopy analyses have been performed for tiles extracted from the toroidal pump limiter of Tore Supra for erosion- and deposition-dominated zones. Deposit thicknesses have been estimated for the plasma-facing top and the gap side lateral surfaces. Deposit thickness profiles have been measured inside gaps, showing that deposition mainly occurs in the first millimetre and that both poloidal and toroidal gap deposition is asymmetric. Quantitative information on the deposit volume and on D-retention are thus obtained from these measurements. Carbon probed at the tile top surfaces is mainly amorphous carbon, due either to the amorphization induced by ion bombardment in the erosion dominated zone, or to deposit formation processes in the deposition-dominated zones. Deposits are tip-shaped and are oriented, which should give information on transport processes.
\end{abstract}

PACS: 52.55.Fa, 52.40 Hf, 68.37 Hk, 81.05.Uw

JNM keywords: Carbon, Electron microscopy, Microstructure and texture, Redeposition, Surface effects

PSI-19 keywords: Tore Supra, erosion and deposition, deuterium inventory, surface analysis, amorphous films.

*Corresponding author e-mail: celine.martin@univ-provence.fr

* Corresponding author address: PIIM, CNRS UMR 6633, service 242, Université de Provence, Centre Saint-Jérôme, 13397 Marseille cedex 20, France. 


\section{Introduction}

Fuel retention in fusion devices limits their future operation due to radioactive or explosive risks. The Deuterium Inventory in Tore Supra (DITS) project is aimed at studying retention in the carbon Plasma Facing Components (PFCs) of Tore Supra (TS). First, a campaign was dedicated to D-loading PFCs by repetitive long pulse plasmas with an in-situ D inventory monitored through particle balance [1]. Then, a sector of the Toroidal Pump Limiter (TPL) was dismantled for an extensive post-mortem analysis of its Carbon Fibre Composite (CFC) tiles, combining techniques devoted to deuterium inventory and structural characterisations [1-3]. Three different zones due to different competition between erosion and deposition have been previously evidenced, the erosion zone $\left(\sim 3.5 \mathrm{~m}^{2}\right)$, the thick deposit zone $\left(\sim 0.5 \mathrm{~m}^{2}\right)$ and the thin deposit zone $\left(\sim 3.0 \mathrm{~m}^{2}\right)[3,1]$, for which almost no deposit, thick and poorly-attached deposits, and thin and well-attached deposit have been observed, respectively.

Using electron microscopy, we have performed a multiscale analysis of the structure of carbon layers resulting from co-deposition process on the TPL tile surfaces. We have analysed the topography and the structure of the deposits at the micrometer scale by scanning electron microscopy (SEM), and their nanostructure (amorphous or graphitic) at the nanometer scale by transmission electron microscopy (TEM). We have analysed both the plasma-facing top surface and the lateral surfaces (in the gaps between tiles) of three types of TPL tiles, extracted from the three zones of interest (Fig. 1).

In this paper, we report first on the top surfaces from the three zones, we then detail what is observed for gap side surfaces, distinguishing gaps in the poloidal and in the toroidal direction. Finally, we estimate the deposit volume from SEM analyses and the contribution to retention of different parts of the TPL is discussed. 


\section{Experimental part and methods}

TS tiles were removed from the erosion zone (tiles F27T10 and F5T3), the thick deposit zone (tiles F27T5 and F28T5), and the thin deposit zone (tiles F10T10 and F17T7), tile numbering convention being FxTy for tile y on finger $x$. The five sides of each tile, the plasma-facing top and the four lateral sides, corresponding to poloidal and toroidal gaps, were analyzed. The two toroidal sides are distinguished using the magnitude of the magnetic field: high field side (HFS) and low field side (LFS), whereas the two poloidal sides are either upor down-stream (Fig.1).

SEM was carried out at the Microscopy Centre (Université de Provence, France) using an ESEM Philips XL 30 microscope with a $5 \mathrm{~nm}$ resolution. The deposit thicknesses have been measured directly using SEM images of flaking deposits showing an edge of the film. For deposits inside porosities the thickness is measured at the entrance of the pores using the top view of the tile. For well-attached deposits in the thin deposit zone, we estimated the values using an empiric correlation between thickness and tip size. The given error bars are to the inhomogeneity of the sample. TEM was carried out at the CP2M laboratory (Marseille, France) using a JEOL 2010F field emission microscope, with a $0.18 \mathrm{~nm}$ structural resolution and a $0.2 \mathrm{~nm}$ spot size. Thin foils $(\sim 100 \mathrm{~nm}$ x $15 \mu \mathrm{m}$ x $5 \mu \mathrm{m})$ were cut by the Focussed Ion Beam (FIB) technique, carried out at the same laboratory using a Philips FIB 200 TEM with a $5 \mathrm{~nm}$ spatial resolution and equipped with a platinum gas injector to coat samples with a protective Pt layer before cutting. We have checked that the FIB technique did not induced any modification of the nanostructure using a graphite sample.

\section{Results and discussion}

\subsection{Plasma-facing top surfaces}

The SEM image of the top surface of the F27T10 tile (Fig. 2a) shows that, in 
comparison with the virgin tile, the surface of eroded tiles is smoothed down due to erosion $[4,5]$. The cross-section of the CFC fibres is clearly visible, due to the topographic contrast generated by the differential erosion of fibres and matrix, fibres being more eroded than matrix [6]. A new regular surface roughness i.e. a striation in an oblique direction is clearly visible in a magnification of Fig. 2a, the distance between grooves being about the fibre size. A detailed study of this striation is under investigation using atomic force microscopy. The intrinsic porosity of CFC is also clearly visible although pores are partially filled by deposits [3] (the deposit thickness is measured here at $\sim 10 \mu \mathrm{m}$ ). This open porosity thus contributes to fuel retention by diffusion and deposition inside, as evidenced from laboratory experiments $[7,8]$, its contribution being estimated at less than $15 \%$ [1].

In the case of the thick deposit F27T5 tile (Fig. 2b), the CFC porosity and structure is not visible and the surface is covered by thick and poorly-attached deposits. We have measured the layer at about $400 \pm 100 \mu \mathrm{m}$ thick, most of the deposits are nevertheless flaking. Fig. $2 \mathrm{~b}$ shows tips lying on the top surface, with size of $\sim$ a few hundred of $\mu \mathrm{m}$. They have a poloidal orientation, always pointing to LFS, and their surface is smooth.

Fig. 2c shows SEM images of the two tiles investigated from the thin deposit zone (F17T7 and F10T10). Similarly to thick deposits, thin deposits are tip-shaped, with a preferential poloidal orientation from HFS to LFS, and with sizes estimated here at $\sim 30$ and $100 \mu \mathrm{m}$, respectively. The deposit thickness strongly varies from tile to tile, the thicker the deposits the larger the tips, and, using an estimated correlation between the tip size and the deposit thickness, the thickness is estimated here at $\sim 20$ and $200 \mu \mathrm{m}$ for F17T7 and F10T10, respectively. Contrary to the thick deposit zone, the CFC porosity is still visible, whatever the deposit thickness. Note that tips observed on the TPL surfaces are very similar to tips previously observed on neutralizers surfaces of TS or TEXTOR [9-11].

This SEM analysis highlights the influence of the deposit on the tile temperature 
previously measured using infrared thermography [5]. The thick deposit zone corresponds to the tangential zone, i.e. the zone where the magnetic field direction is almost tangential, at less than $1^{\circ}$ in the vertical direction [5], parallel ion fluxes are very limited and deposition rate is high. Even though heating due to bombardment is limited, the surface temperature can raise high values such as $1000^{\circ} \mathrm{C}$ because deposits are poorly-attached and then in bad thermal contact with the underlying active cooling system. In the thin deposit zone, the surface temperature remains at $120^{\circ} \mathrm{C}$, i.e. at the temperature of the cooling water loop, showing that whatever their thickness, deposits are well-attached and in a good thermal contact.

In the erosion zone, TEM analyses performed on thin FIB foils have revealed the presence of a thin amorphous carbon layer $(30 \pm 10 \mathrm{~nm}$, see Fig. 3a), covering the graphitic carbon of CFC. In the case of the thick and thin deposit zones, similar analyses have revealed that deposits are composed of amorphous carbon $(15 \mu \mathrm{m}$ is the maximum depth analysed when using FIB foil preparation). In the erosion zone, the plasma-wall interactions are dominated by high heat and ion fluxes $[4,5]$ and the tile surface is significantly eroded (up to $700 \mu \mathrm{m})$. The thin amorphous layer observed is due to ion implantation and to the amorphization induced by bombardment, contrary to amorphous carbon of deposition zones (Fig. 3b and 3c) which results from complex physical and chemical carbon layer formation processes.

\subsection{Poloidal and toroidal gaps}

Fig. 4 shows SEM images obtained for the poloidal gap sides of the F27T10 tile from the erosion zone. Thick deposited layers are observed at the entrance of the gap whereas at the bottom of the gap the CFC structure is still visible (bundles of fibres and metallic cones due to active metal casting [12]). At the gap entrance of the up- and down-stream sides (Fig 4a and $4 \mathrm{~b}$ respectively), tips are lying on the surface, pointing to $\sim 45^{\circ}$ at the top - LFS direction, 
with a size of $\sim 100 \mu \mathrm{m}$, this size decreasing when going deeper in the gap, and tips disappearing under $\sim 1 \mathrm{~mm}$. An asymmetry between the up-stream and the down-stream gaps for the edge shape and the surface roughness has been found: for tile F27T10, the up-stream edge is sharp and tips are rough, while the down-stream edge is curved and tips are smooth. The opposite is observed for tile F5T3. Fig. 5 shows the detailed profiles of the curved and sharp poloidal edges (Fig. 5a and 5b, respectively) measured by SEM for pieces cut from the F27T10 tile. This asymmetry may be related to the poloidal component of the flux parallel to the surface whose sign changes when crossing the thick deposit zone, i.e the tangential zone, which is in between these two tiles. The curved and smooth edges therefore could correspond to deposition under ion bombardment while the sharp and rough edges could correspond to shadowed deposition.

On the toroidal gap sides, thick and poorly-attached deposits are observed with a strong asymmetry: their thickness at the entrance of the gap is about $300 \mu \mathrm{m}$ for the LFS side and less than $100 \mu \mathrm{m}$ for the HFS side. This toroidal asymmetry could be related to plasma fluxes modeled using PIC calculations [13]. Similarly to what is observed for the poloidal gaps, there is no deposition under $\sim 1 \mathrm{~mm}$.

\subsection{Contribution to retention}

Table 1 summarizes volumes of deposits, $\mathrm{V}_{\mathrm{d}}$, obtained from SEM measurements for the top surfaces of the three zones and the corresponding relative volumes, $\eta_{v}$. For the thin deposit zone, a mean estimated deposit thickness of $110 \mu \mathrm{m}$ has been considered. For the erosion and thick deposit zones, the measured deposit thickness of $30 \mathrm{~nm}$ and $400 \mu \mathrm{m}$ has been taken, respectively. As expected, the contribution of the erosion zone is negligible compared to those of the thick and thin deposit zones. The main contribution comes from the thin deposit zone, due to its large surface area. Assuming a D content similar for all the deposits [14], $\eta_{\mathrm{v}}$ can be compared to the relative D-retention previously estimated by NRA 
and TDS, called here $\eta_{D}$. Our SEM analyses are thus in good agreement with these previous DITS analyses [2], except for the erosion zone. To explain this, note that NRA and TDS analyses also take into account $\mathrm{D}$ retention due to bulk diffusion and deposition inside porosities. The difference between the two estimations thus emphasizes the role played by porosities in retention.

The deposit volume inside the gaps of the erosion zone is estimated at $\sim 100 \mathrm{~cm}^{3}$ from the profile measurements of Fig. 5. This shows that, in the erosion zone, the deposit volume (and thus the D retention) is of the order of magnitude of that due to top surfaces of thin and thick deposits zones (table 1). This confirms that gaps play an important role in the total retention.

\section{Conclusion}

Tiles from the three zones of interest (erosion, thin deposit and thick deposit zones) have been analysed using SEM. Clear structures were observed at the surface of the different zones: up/down-stream and HFS/LFS asymmetries on the edges of the gaps, poloidal orientation of the tips in the deposit regions, orientation of the striations in the erosion zones. These structures are likely linked to the pattern of the plasma flux on the limiter surface and their analysis could yield valuable information on the direction and importance of drifts close to the surface of the TPL.

We have observed that thin deposits are well-attached deposits, even though their thickness is very inhomogeneous and can reach similar values than that of thick deposits which are most often poorly-attached. Tiles from the thin deposit zone could therefore contribute very differently to the $\mathrm{D}$ retention and care should then be taken when estimating the contribution of thin deposits to retention from the analysis of a limited number of tiles. In the erosion zone, an amorphized carbon layer of a few tens of nm covering CFC has been 
evidenced. The contribution to retention is nevertheless negligible compared to that of porosities.

Finally, this paper gives the first steps to estimate D retention from SEM estimation of deposit volumes, and the complete estimation is ongoing, together with the achievement of full consistency with complementary Raman, NRA and TDS and TEM measurements.

Acknowledgments We acknowledge the Euratom-CEA association, the Fédération de Recherche FR-FCM, the EFDA European Task Force on Plasma Wall Interactions, the French agency ANR (ANR-06-BLAN-0008 contract) for financial support. 


\section{References}

[1] B. Pégourié, C. Brosset, E. Tsitrone, et al., J. Nucl. Mater. 390 (2009) 550.

[2] E. Tsitrone, C. Brosset, B. Pégourié, et al., Nuclear Fusion 49, 075011 (2009).

[3] T. Dittmar, P. Roubin, E. Tsitrone, et al., Physica Scripta T138 (2009).

[4] E. Delchambre, A. Beaute, S. Brezinsek, et al., J. Nucl. Mater., 390 (2009) 65.

[5] S. Carpentier, Y. Corre, M. Chantant, et al., J. Nucl. Mater., 390 (2009) 955.

[6] X. Liu, Z.Y. Xu, J.M. Chen, L.W. Yan and Y. Liu, J. Nucl. Mater., 307 (2002) 84.

[7] J. Roth, V. K. Alimov, A. V. Golubeva et al. J. Nucl. Mater., 363 (2007) 822.

[8] N. Bernier, C. Brosset, F. Bocquet et al. J. Nucl. Mater., 385 (2009) 601.

[9] C. Martin, M. Richou, W. Saikaily et al., J. Nucl. Mater., 363 (2007) 1251.

[10] M. Rubel, V. Philipps, T. Tanabe, et al. Physica Scripta T103 (2003) 20.

[11] M. Richou, C. Martin, P. Delhaès, et al., Carbon 45 (2007) 2723.

[12] R. Mitteau, P. Chappuis, L. Moncel and J. Schlosser, J. Nucl. Mater., 258 (1998) 972.

[13] R. Dejarnac and J.P. Gunn, J. Nucl. Mater., 363 (2007) 560.

[14] C. Pardanaud, G. Giacometti, C. Martin et al., this conference. 
Table 1: SEM analyses of deposits from the plasma-facing top surfaces of TPL tiles: deposit thickness, $\delta(\mu \mathrm{m})$, total tile surface, $\mathrm{S}\left(\mathrm{m}^{2}\right)$, estimated deposit volume, $\mathrm{V}_{\mathrm{d}}\left(\mathrm{cm}^{3}\right)$, relative volume from each zone, $\eta_{\mathrm{v}}(\%)$, relative $\mathrm{D}$ retention rate previously estimated with the DITS project [2], $\eta_{D}(\%)$.

\begin{tabular}{lccccc}
\hline Zone & $\delta$ & $\mathrm{S}$ & $\mathrm{V}_{\mathrm{d}}$ & $\eta_{\mathrm{v}}$ & $\eta_{\mathrm{D}}$ \\
\hline Erosion & 0.03 & 3.5 & 0.1 & 0.02 & 18 \\
Thin deposit & 110 & 3 & 330 & 62 & 51 \\
Thick deposit & 400 & 0.5 & 200 & 38 & 31 \\
\hline
\end{tabular}




\section{Figure Captions}

Figure 1: Picture of the TS TPL showing the three zones of interest and the tiles investigated.

Figure 2: Structure of the plasma-facing top surface of TPL tiles: (a) tile F27T10 from the erosion zone and magnification showing the CFC fibres cross section, (b) tile F27T5 from the thick deposit zone and (c) tile F17T17 (on left) and F10T10 (on right) from the thin deposit zone. All theses images are oriented with LFS side on top.

Figure 3: TEM micrographs of FIB foils cut from the plasma-facing top surface of TPL tiles: (a) tile F27T10 from the erosion zone showing a thin amorphous carbon layer on a CFC fibre, (b) tile F27T5 from the thick deposit zone and (c) tile F10T10 from thin deposit zone. The dark zone is the Pt coating used to protect samples before cutting.

Figure 4: Structure of the deposit on the gap side surfaces of tile F27T10 from the erosion zone (a) entrance of the up-stream poloidal gap (b) entrance of the down-stream poloidal gap and (c) and entire up-stream poloidal gap from entrance to bottom.

Figure 5: Deposit thickness profile inside the two poloidal gaps of tile F27T10 from the erosion zone with SEM images of each gap edge, (a) up-stream poloidal gap (b) down-stream poloidal gap. The dotted (...) and dash-dotted (.-.-.) lines correspond to the positions of the tile and the deposit surfaces, respectively. 
Figure 1

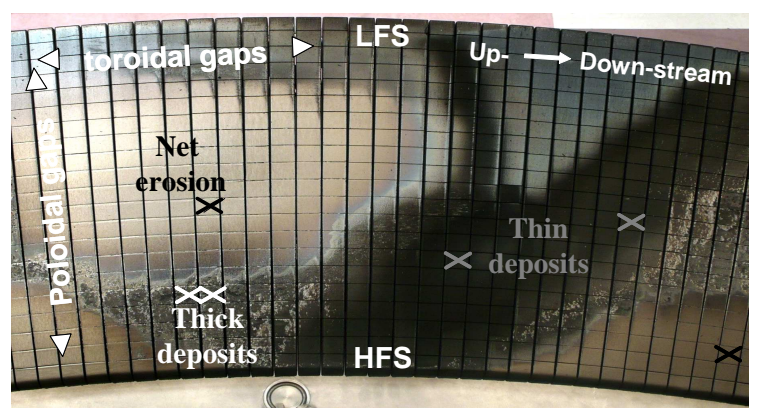


Figure 2

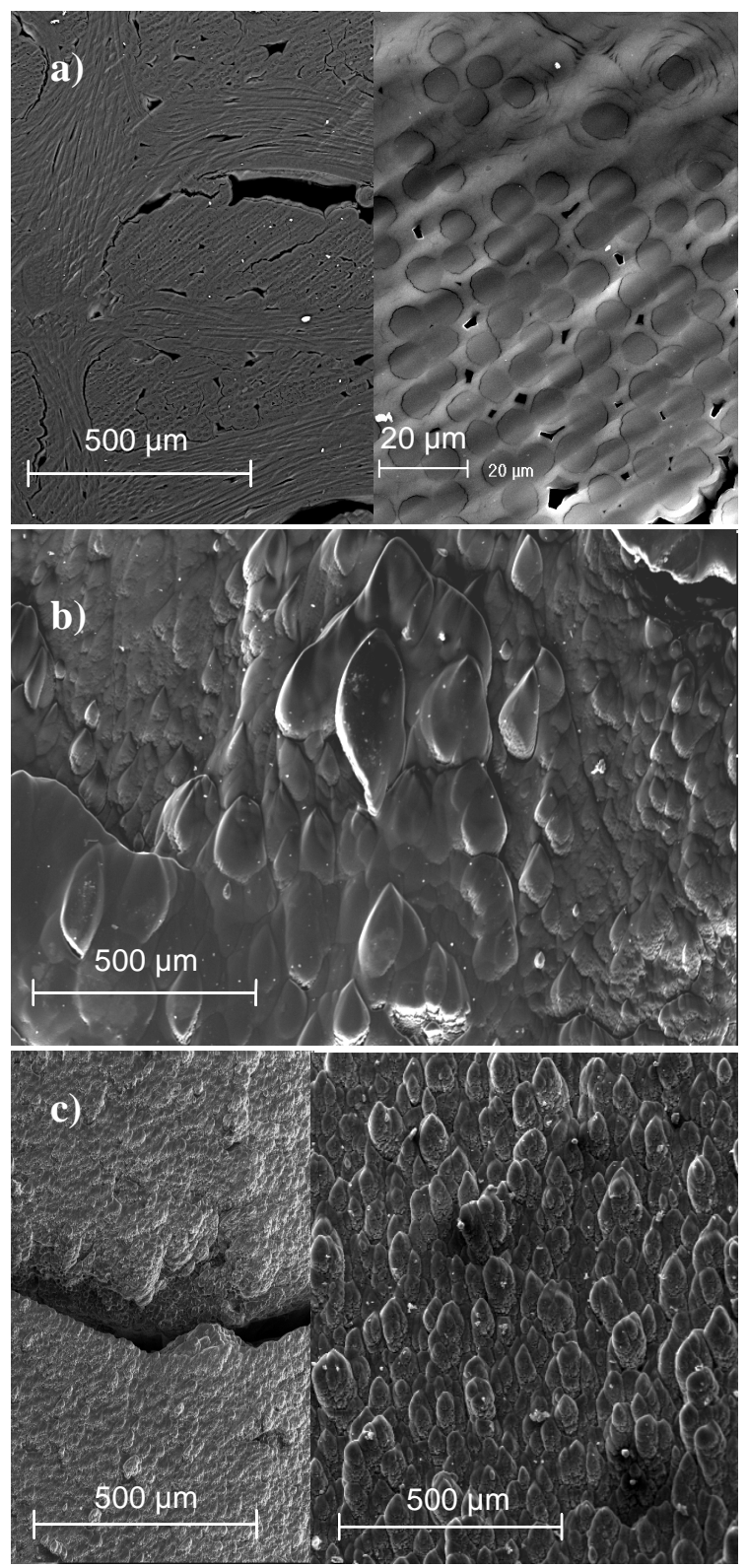


Figure 3

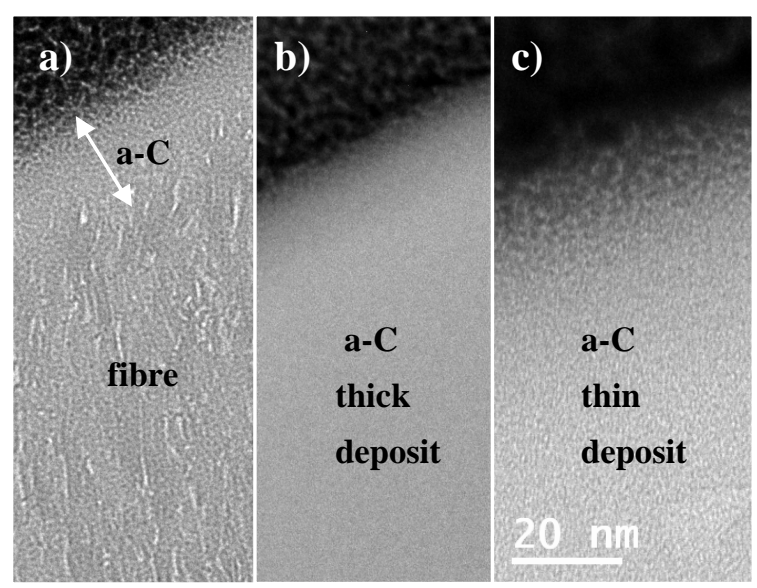


Figure 4

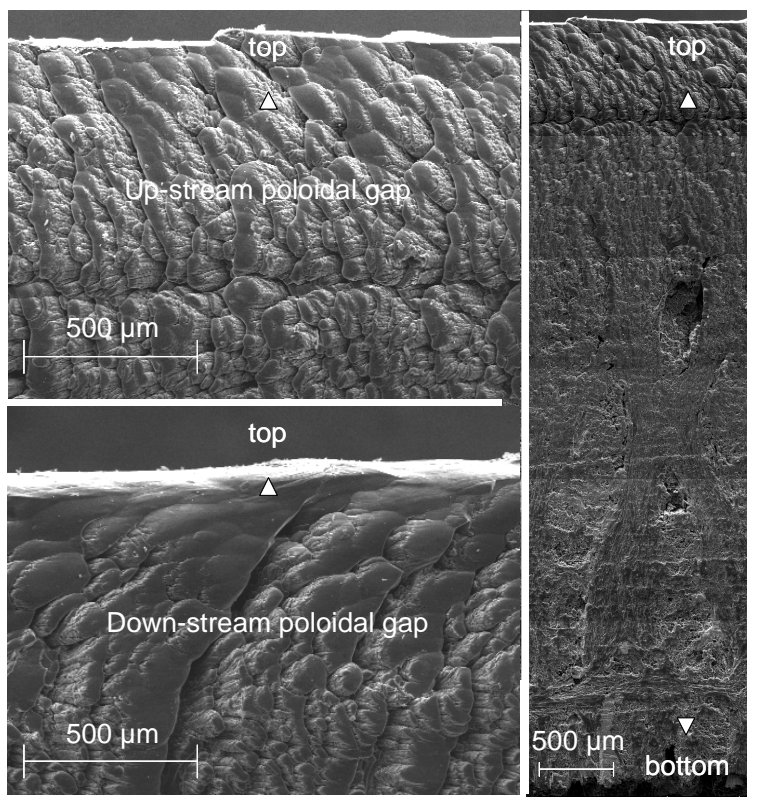


Figure 5

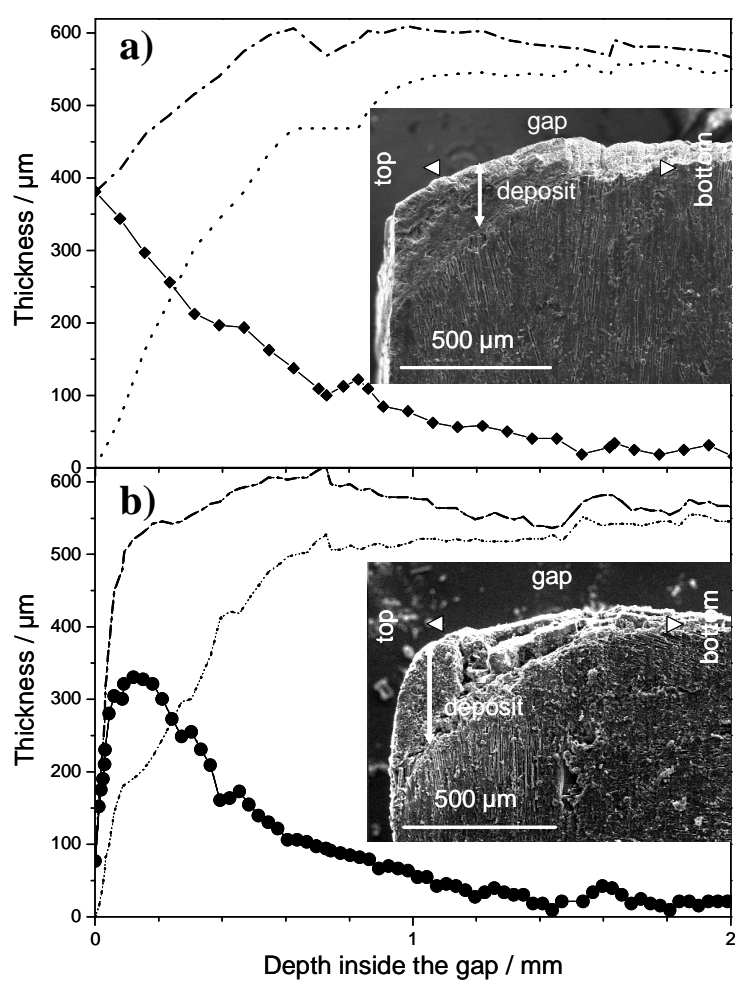

